\title{
EFEK PEMBERIAN BUAH PISANG PADA PENURUNAN KELELAHAN KERJA BAGI PEKERJA DI BAGIAN PELINTINGAN ROKOK
}

\author{
Yusuf Ari Mashuri'1), Zara Offia Sweetry'), Ipop Sjarifah ${ }^{3)}$ \\ 1),2),3) Fakultas Kedokteran, Universitas Sebelas Maret \\ E-mail : yusufmashuri@staff.uns.ac.id
}

\begin{abstract}
Manual rolling work can cause work fatigue due to high job targets. Banana (Musa sapientum) contains natural sugars such as sucrose, fructose, and glucose as a source of energy. Work fatigue can be overcome with energy supplementation such as banana. This study aimed to determine the effect of banana supplementation on the level of work fatigue of cigarette manual rolling workers in X factory Karanganyar. This research was a quasi-experimental, with a one-shot case study design. The sampling technique used was simple random sampling, A total of 54 workers was randomly recruited as the sample. The independent variable of this study was banana (Musa sapientum), while the dependent variable was work. fatigue. The Wilcoxon test was used to analyze the data. The Wilcoxon test showed that there was a significant difference between work fatigue before and after the banana supplementation to the cigarette manual rolling worker of X factory Karanganyar (p-value $=0.000)$. Thus, Banana (Musa sapientum) can be given as a food supplement to overcome the work. fatigue problems in manual rolling workers.
\end{abstract}

Keywords: Banana; Work Fatigue; Workers.

\begin{abstract}
ABSTRAK
Pekerjaan pelintingan manual dapat mengakibatkan kelelahan kerja karena target pekerjaan yang tinggi. Buah pisang raja (Musa sapientum) mengandung gula alami seperti sukrosa, fruktosa dan glukosa sebagai sumber energi. Kelelahan kerja dapat diatasi dengan pemberian energy dari buah pisang raja. Penelitian ini bertujuan untuk mengetahui apakah ada efek pemberian buah pisang raja pada tingkat kelelahan kerja pada pekerja pelintingan manual Perusahaan Rokok X Karanganyar. Jenis penelitian ini adalah quasi experimental, dengan desain one shot case study design. Teknik sampling yang digunakan adalah simple random sampling, dengan total sampel sebesar 54 pekerja. Variabel bebas penelitian ini adalah buah pisang raja, sedangkan variabel terikat adalah kelelahan kerja. Uji Wilcoxon digunakan untuk menganalisis data. Uji Wilcoxon menunjukkan terdapat perbedaan yang signifikan antara kelelahan kerja sebelum dan sesudah pemberian buah pisang raja pada pekerja pelintingan manual Perusahaan Rokok X Karanganyar $(p$-value $=0,000)$. Oleh karena itu
\end{abstract}

Cara mengutip: Mashuri, Y. Ari., Sweetry, Z., Offia., \& Sjarifah, Ipop. (2020). Efek Pemberian Buah Pisang Pada Penuruan Kelelahan Kerja Bagi Pekerja di bagian Pelintingan Rokok.Care:Jurnal Ilmiah Ilmu Kesehatan, 8(3), 338-345 
buah pisang raja dapat diberikan sebagai tambahan makanan dalam mengatasi permasalahan kelelahan kerja pada pekerja pelintingan manual.

Kata Kunci : Buah Pisang; Kelelahan Kerja; Pekerja Pelintingan.

\section{PENDAHULUAN}

Kelelahan kerja merupakan penurunan efisiensi dan ketahanan fisik manusia untuk melakukan pekerjaan. Tingkat kelelahan yang dirasakan oleh pekerja dapat menyebabkan penurunan produktivitas. Kelelahan kerja dapat disebabkan faktor lingkungan kerja, individu dan pekerjaan. Kelelahan tidak hanya dirasakan ketika melakukan suatu pekerjaan, tetapi juga akan dirasakan sebelum melakukan pekerjaan (Suroto, 2016)

Berdasarkan data International Labor Organization(2018), terdapat 2,78 juta pekerja meninggal setiap tahun karena kecelakaan kerja dan penyakit akibat kerja. Sekitar 380 ribu $(13,7 \%)$ pekerja meninggal karena kecelakaan yang salah satu penyebabnya adalah kelelahan kerja. Departemen Tenaga Kerja dan Transmigrasi (Depnakertrans) Indonesia pada tahun 2004 melaporkan rata-rata setiap hari terjadi 414 kecelakaan kerja, $27,8 \%$ disebabkan kelelahan yang cukup tinggi, kurang lebih 9,5\% atau 39 orang mengalami cacat (Atiqoh, 2014).
Peraturan Menteri Tenaga Kerja dan Transmigrasi No: PER.03/MEN/1982 Tentang Pelayanan Kesehatan Tenaga Kerja Pasal 2 menyatakan bahwa untuk melindungi tenaga kerja terhadap setiap gangguan kesehatan yang timbul dari pekerjaan, lingkungan kerja, dan kemampuan fisik dari tenaga kerja maka perlu adanya perhatian terhadap gizi pekerja. Asupan gizi penting bagi tenaga kerja, karena tenaga kerja membutuhkan bahan makanan untuk memenuhi kebutuhan energi untuk melakukan aktivitas fisik yaitu bekerja (Kemenakretrans, 1982).

Pisang (Musa paradisiaca) merupakan buah yang sangat mudah ditemukan dan harga yang terjangkau. Buah pisang mengandung gula alami seperti sukrosa, fruktosa dan glukosa. Buah pisang memiliki tekstur daging buah yang lunak sehingga mudah dicerna dalam tubuh (Wulandari, 2018). Kandungan pada buah pisang berupa karbohidrat sederhana dan komplek baik digunakan sebagai sumber energi (Ismanto, 2015). Komponen karbohidrat terbesar pada buah pisang adalah pati pada daging buahnya, dan 
akan diubah menjadi sukrosa, glukosa dan fruktosa pada saat pisang matang (Falcomer, Riquette, De Lima, Ginani, \& Zandonadi, 2019; Nieman et al., 2012). Penelitian Ginting (2017) menunjukkan terjadi peningkatan kadar glukosa darah pada kelompok eksperimen setelah mengkonsumsi buah pisang. Peningkatan glukosa darah tersebut dapat menurunkan angka kelelahan (Kumairoh, 2014). Tujuan penelitian ini adalah mengetahui efek pemberian buah pisang raja pada tingkat kelelahan kerja pada pekerja bagian pelintingan manual perusahaan Rokok X Karanganyar.

\section{METODE PENELITIAN}

Jenis penelitian ini adalah quasi experimental dengan rancangan One Shot Case Study design. Penelitian dilaksanakan di bagian pelintingan manual Perusahaan Rokok X Karanganyar pada bulan Juni 2019. Populasi penelitian ini adalah seluruh tenaga kerja perempuan yang bekerja di bagian pelintingan manual yang berjumlah 63 orang. Kriteria sampel pada penelitian ini adalah pekerja yang telah bekerja lebih dari dua tahun, tidak memiliki alergi makanan pisang, tidak menderita diabetes melitus, dan keluhan pencernaan. Simple random sampling digunakan untuk memilih sampel dengan jumlah 54 orang.
Variabel bebas penelitian ini adalah buah pisang raja, sedangkan variabel terikat adalah kelelahan kerja. Buah pisang raja (Musa sapientum) masak seberat \pm 300 gram diberikan setelah dua jam bekerja yaitu pada pukul 09.00 WIB pada periode pemberian selama empat hari berturutturut. Kelelahan kerja diukur dengan menggunakan alat reaction timer rangsang cahaya pada saat sesudah bekerja tanpa istirahat pada pukul 09.00 WIB. Pemeriksaan dilakukan dengan cara pekerja menekan mouse bila melihat kelipan cahaya yang diulang sebanyak 20 kali. Kelelahan kerja diukur selama empat hari sebelum pemberian buah pisang raja dan empat hari saat pemberian buah pisang raja. Rata-rata kelelahan kerja sebelum dan setelah pemberian buah pisang raja kemudian dikategorikan menjadi empat kriteria yaitu: 1) normal dengan waktu reaksi 150,0 - 240,0 milidetik; 2) ringan dengan waktu reaksi 240,0 $<\mathrm{x}<410,0$ milidetik; 3) sedang dengan waktu reaksi 410,0 $<\mathrm{x}<580,0$ milidetik; dan 4) berat dengan waktu reaksi $>580,0$ milidetik.

Persetujuan etik didapatkan dari komite etik RSUD Dr. Moewardi Surakarta. Tiap responden mendapatkan informasi yang jelas tentang penelitian dan 
menandatangani lembar persetujuan.

Data dianalisis menggunakan SPSS versi

21 dengan uji Wilcoxon. Nilai $\mathrm{p}<0.05$ dianggap sebagai hasil yang signifikan.

\section{HASIL}

Tabel 1. DistribusiFrekuensiUsia

\begin{tabular}{crr}
\hline Usia (Tahun) & f & \multicolumn{1}{c}{$(\mathbf{\% )}$} \\
\hline$<25$ & 1 & 1,9 \\
$26-35$ & 5 & 9,3 \\
$36-45$ & 5 & 9,3 \\
\hline $46-55$ & 41 & 75,9 \\
$56-65$ & 2 & 3,7 \\
\hline Total & 54 & 100 \\
\hline
\end{tabular}

Berdasarkan tabel 1 dapat diketahui bahwa responden yang paling banyak ada pada rentang usia 46-55 tahun yaitu sebanyak 41 responden $(75,9 \%)$, sedangkan 1 responden $(1,9 \%)$ berada pada rentang usia di bawah 25 tahun. Seluruh responden berjenis kelamin perempuan.

Tabel 2. Distribusi Frekuensi Masa Kerja

\begin{tabular}{ccc}
\hline $\begin{array}{c}\text { Masa Kerja } \\
\text { (Tahun) }\end{array}$ & $\mathbf{N}$ & $\mathbf{( \% )}$ \\
\hline$<10$ & 4 & 7,4 \\
$>10$ & 50 & 92,6 \\
\hline Total & 54 & 100 \\
\hline
\end{tabular}

Berdasarkan tabel 2, frekuensi masa kerja tertinggi adalah $>10$ tahun sejumlah 50 responden $(92,6 \%)$, hanya 4 responden $(7,4 \%)$ yang memiliki masa kerja $<10$ tahun.

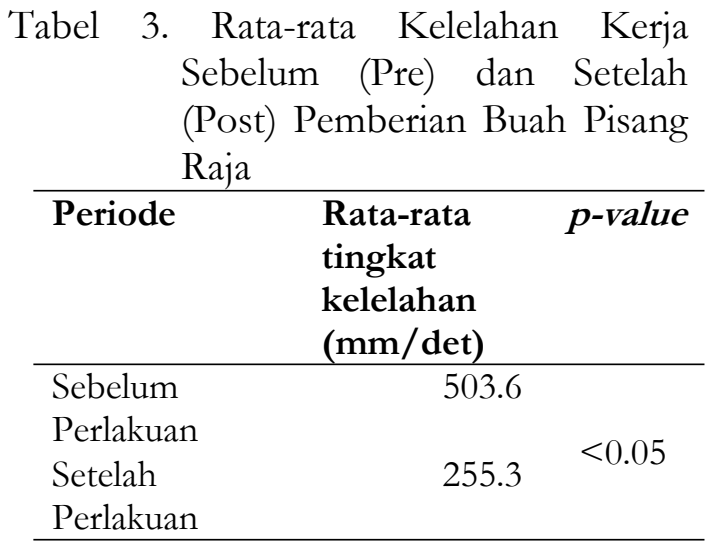

Tabel 4. Distribusi Frekuensi Kelelahan Kerja Sebelum(Pre) dan Setelah (Post) Pemberian Buah Pisang Raja

\begin{tabular}{lrr}
\hline $\begin{array}{l}\text { Tingkat } \\
\text { kelelahan }\end{array}$ & $\begin{array}{c}\text { N (\%) } \\
\text { Pre }\end{array}$ & N (\%) Post \\
\hline Normal & & $4(7,4)$ \\
Ringan & - & $49(90,7)$ \\
Sedang & $51(94,4)$ & $1(1,9)$ \\
Berat & $3(5,0)$ & - \\
\hline Total & $54(100)$ & $54(100)$ \\
\hline
\end{tabular}

Hasil pengukuran tingkat kelelahan kerja sebelum pemberian buah pisang raja menunjukkan angka 503,6 $\mathrm{mm} /$ det. Sedangkan tingkat kelelahan kerja setelah pemberian buah pisang raja adalah 255,3 $\mathrm{mm} /$ det (Tabel 3). Berdasarkan hasil pengukuran sebelum pemberian buah pisang raja, terdapat $51 \quad(94,4 \%)$ responden mengalami kelelahan sedang dan tiga $(5,6 \%)$ responden mengalami kelelahan berat (Tabel 4).

Hasil tingkat kelelahan setelah pemberian buah pisang raja menunjukkan empat $(7,4 \%)$ responden tidak mengalami kelelahan kerja, $49(90,7 \%)$ mengalami 
kelelahan kerja ringan dan satu (1,9\%) responden mengalami kelelahan kerja sedang. Tidak terdapat pekerja yang mengalami kelelahan kerja berat.

Tabel 5.Hasil Analisis Uji Wilcoxon

\begin{tabular}{cc}
\hline Variabel & $\boldsymbol{p}$-value \\
\hline Kelelahan kerjaPre-Intervensi vs Post-Intervensi & $0,000(<0,05)$ \\
\hline
\end{tabular}

Hasil uji beda dengan analisis Wilcoxon antara kelelahan kerja sebelum pemberian buah pisang raja dengan kelelahan kerja setelah pemberian buah pisang raja menunjukkan nilai $\mathrm{p}=0,000(\mathrm{p}<0,05)$. Hal tersebut menunjukkan ada perbedaan kelelahan kerja yang signifikan sebelum dan sesudah pemberian buah pisang raja.

\section{PEMBAHASAN}

Usia merupakan salah satu faktor yang memiliki kontribusi dalam kelelahan. Usia responden yang terlibat dalam penelitian ini memiliki usia kurang dari 60 tahun. Mayoritas responden berada pada rentang usia 46-55 tahun. Hal ini sesuai dengan data usia produktif orang Indonesia menurut Kementrian Kesehatan yaitu 1564 tahun (Kemenkes RI, 2016). Menurut Maurits (2010) usia merupakan variabel yang berpengaruh terhadap perasaan kelelahan kerja. Usia mempengaruhi ketahanan tubuh dan kapasitas kerja seseorang. Pada usia 20 tahun merupakan puncak dari kekuatan otot seseorang baik lak-laki maupun perempuan, dan pada usia sekitar 50-60 tahun kekuatan otot mulai menurun sekitar 15-25\% (Lusiana, 2014).

Pada penelitian ini seluruh responden berjenis kelamin perempuan. Jenis kelamin merupakan salah satu faktor yang dapat mempengaruhi tingkat kelelahan kerja. Secara umum, terdapat perbedaan ukuran tubuh dan kekuatan otot antara laki-laki dan perempuan terletak pada ukuran tubuh dan kekuatan ototnya. Kekuatan otot perempuan relatif kurang jika dibandingkan dengan kekuatan otot laki-laki. Kekuatan otot akan mempengaruhi kemampuan kerja seseorang yang merupakan penentu terjadinya kelelahan (Suma'mur, 2014).

Seluruh responden telah bekerja selama lebih dari dua tahun dan mayoritasresponden telahbekerja lebihdari10 tahun. Maurits (2010) menyebutkan, semakin lama masa kerja seseorang maka semakin tinggi juga tingkat kelelahan, karena semakin lama bekerja menimbulkan perasaan jemu akibat kerja monoton. Paulina and Salbiah (2016) menyebutkan, semakin 
lama masa kerja pekerja maka semakin tinggi pekerja beresiko kelelahan. Hasil pengukuran tingkat kelelahan sebelum pemberian buah pisang raja menunjukkan lebihdarisetengah total responden memiliki tingkat kelelahan kerja sedang. Kelelahan ini berhubungan dengan aktivitas yang dilakukan secara terus menerus. Aktivitas tersebut akan mengurangi cadangan sumber energi dan menyebabkan terakumulasinya asam laktat dalam otot sehingga kemampuan otot berkontraksi akan menurun dan menyebabkan terjadinya kelelahan otot (Kumairoh, 2014). Hasil pengukuran kelelahan kerja setelah pemberian buah pisang raja menunjukkan mayoritas responden memiliki tingkat kelelahan kerja ringan. Hasil tersebut menunjukkan penurunan tingkat kelelahan kerja yang dialami pekerja dibanding dengan sebelum pemberian buah pisang raja.

Hasil uji Wilcoxon menunjukkan hasil perbedaan yang signifikan antara kelelahan kerja pekerja bagian pelintingan manual Perusahaan Rokok X Karanganyar sebelum dan sesudah pemberian buah pisang raja. Kombinasi zat gizi pada buah pisang berpotensi mengatasi kelelahan kerja, kandungan berupa karbohidrat sederhana dan kompleks baik digunakan sebagai sumber energi. Ketika otot mulai kekurangan enegi glikogen dalam hati akan dipecah sehingga level glukosa darah dan laju pembakaran karbohidrat dapat dipertahankan untuk memenuhi kebutuhan energi otot. Karbohidrat yang disimpan dalam jumlah terbatas akan menurunkan kemampuan tubuh untuk mempertahankan performa sehingga mengakibatkan terjadinya kelelahan (Falcomer, 2019; Imam and Akter, 2011; Ismanto, 2015; Kementerian Kesehatan RI, 2018)

Hasil penelitian ini juga sejalan dengan penelitian yang dilakukan oleh Damantalm (2018) di PT SSD Kalimantan Timur dengan hasil turunnya tingkat kelelahan kerja yang signifikansetelah pemberian buah pisang pada pekerja pemanen kelapa sawit. Penelitian lain oleh Kumairoh (2014) pada atlet sepak takraw menunjukkan perbedaan nilai Anaerobic Fatigue yang bermakna pada kelompok perlakuan setelah pemberian 150 gram buah pisang.

Penelitian ini memiliki beberapa kelebihan. Pertama, penelitian dilakukan di tempat kerja yang memilki ritme kerja konstan dengan sifat kerja yang repetitif. Hal ini memungkinkan responden mengalami paparan beban kerja yang 
sama baik pada saat sebelum maupun sesudah pemberian buah pisang raja. Kedua, buah pisang raja sebagai bentuk intervensi diberikan dalam berat yang sama bukan berbentuk buah asli. Hal ini memungkinkan adanya intervensi yang seragam pada seluruh responden.

Akan tetapi, terdapat pula kelemahan dalam penelitian ini. Pertama, jenis asupan responden sebelum tidak dikontrol. Hal ini mungkin berpengaruh pada variasi banyaknya sumber energi yang digunakan oleh responden sebelum dan selama bekerja. Kedua, factor perancu seperti kadar gula darah responden tidak terukur. Hal ini dapat mempengaruhi hasil pengukuran sebelum dan sesudah pemberian buah pisang raja. Ketiga, penelitian ini tidak menggunakan kelompok kontrol. Penggunaan kelompok kontrol dapat lebih memastikan apakah penurunan tingkat kelelahan kerja adalah efek dari pemberian buah pisang raja atau karena hal lain.

\section{KESIMPULAN}

Pemberian buah pisang raja mampu menurunkan tingkat kelelahan kerja pada pekerja bagian pelintingan manual Perusahaan Rokok X Karanganyar. Oleh karena itu buah pisang raja dapat dipertimbangkan diberikan sebagai tambahan makanan dalam mengatasi permasalahan kelelahan kerja pada pekerja pelintingan manual.

\section{SARAN}

Perlunya pemberian makanan tambahan yang bergizi, seperti buah pisang raja, minimal satu kali saat bekerja pada pekerja agar dapat menurunkan tingkat kelelahan selama bekerja. Direkomendasikan bagi peneliti selanjutnya agar dapat mengembangkan penelitian dengan menggunakan kelompok kontrol dan mengkontrol factor perancu lain untuk memastikan adanya efek dan mengurangi bias penelitian.

\section{REFERENSI}

Atiqoh, J., Wahyuni, I., \& Lestantyo, D. (2014). Faktor-Faktor yang Berhubungan dengan Kelelahan Kerja pada Pekerja Konveksi Bagian Penjahitan di CV. Aneka Garment Gunungpati Semarang. Jurnal Kesehatan Masyarakat (e-Journal), 2(2), 119-126.

Damantalm, Y., Tirtayasa, K., Adiatmika, I. P. G., Manuaba, Ida Bagus Adnyana Sutjana, I. D. P., \& Sudiajeng, L. (2018). Consumption Of Banana, Short Rest And Stretching In Reducing Musculosceletal Problems, Exhaution And Increasing Of Permanent User Productivity Of Egrek Tools In Palm Coconut Farm Of PT. SSD Berau - East 
Kalimantan. The Indonesian Journal of Ergonomic, 4(1), 47-56.

Falcomer, A. L., Riquette, R. F. R., De Lima, B. R., Ginani, V. C., \& Zandonadi, R. P. (2019). Health benefits of green banana consumption: A systematic review. Nutrients, 11(6), 1-22. https://doi.org/10.3390/nu110612 22

Ginting, A. A. (2017). Konsumsi Pisang Ambon pada Aktivitas Fisik Submaksimal Meningkatkan Kadar Glukosa Darah. Helper, 34(2), 47-52. Retrieved from http://jurnal.unipasby.ac.id/index.p $\mathrm{hp} /$ helper/article/view/465

Imam, M. Z., \& Akter, S. (2011). Musa paradisiaca 1 . and musa sapientum 1 . A phytochemical and pharmacological review. Journal of Applied Pharmacentical Science, 1(5), 14-20.

International Labor Organization. (2018). Meningkatkan Keselamatan dan Kesehatan Pekerja Muda. Kantor Perburuban Internasional , $\mathrm{CH}-1211$ Geneva 22, Switzerland.

Ismanto, H. (2015). Pengolahan tanpa limbah tanaman pisang. Batangkaluku: Balai Besar Pelatihan Pertanian.

Kemenkes RI. (2016). Buku Saku Data dan Informasi. https://doi.org/10.1007/s13398014-0173-7.2

Kementerian Kesehatan RI. (2018). Data Komposisi Pangan Indonesia. Retrieved from http://www.panganku.org/idID/view

Kementerian Tenaga Kerja dan Transmigrasi. (1982). Permenakertrans No 3 Tabun 1982.
Kumairoh, S. (2014). Pengaruh Pemberian Pisang (Musa paradisiaca) Terhadap Kelelahan Otot Anaerob pad Atlet Sepak Takraw. Journal of Nutrition College Diponegoro University, 1-25.

Lusiana, D., Zahroh, S., \& Baju, S. (2014). Factors Caused Fatigue among Furniture Workers. Jurnal Kesehatan Masyarakat Nasional, 8(8), 386-392.

Maurits, L. S. K. (2010). Selintas tentang Kelelahan Kerja. Yogyakarta: Amara Books.

Nieman, D. C., Gillitt, N. D., Henson, D. A., Sha, W., Shanely, R. A., Knab, A. M., ... Jin, F. (2012). Bananas as an energy source during exercise: A metabolomics approach. PLoS ONE, 7(5), 4-10. https://doi.org/10.1371/journal.po ne.0037479

Paulina, \& Salbiah. (2016). Faktor-Faktor Yang Berhubungan Dengan Kelelahan Pekerja di PT Kalimantan Steel. Vokasi Kesehatan, II(2), 165172.

Suma'mur. (2014). Higiene: Perusahaan Dan Kesehatan Kerja (Hiperkes). Jakarta: Sagung Seto.

Suroto, S., Widjasena, B., \& Buwana, P. (2016). Pengaruh Pemberian Air Kelapa Muda (Cocos nucifera) terhadap Kelelahan Kerja pada Nelayan di Tambak Mulyo Semarang. Jurnal Kesehatan Masyarakat (e-Journal), 4(1), 350-358.

Wulandari, R. T., Widyastuti, N., \& Ardiaria, M. (2018). Perbedaan Pemberian Pisang Raja dan Pisang Ambon terhadap VO2Max pada Remaja di Sekolah Sepak Bola. Journal of Nutrition College Diponegoro University, 7(1), 8-14. 